\title{
The Application of Tourism Management Three-dimensional Practical Training Mode in University-enterprise Cooperation
}

\author{
Wenjing Guo ${ }^{1}$ \\ ${ }^{1}$ Qinhuangdao Branch of Northeast Petroleum University, Qinhuangdao, China \\ Correspondence: Wenjing Guo, Department of Tourism, Qinhuangdao Branch of Northeast Petroleum University, \\ 550, West Hebei Street, Haigang District, Qinhuangdao, Hebei, China, 066004. E-mail: 867108548@qq.com
}

Received: April 24, $2014 \quad$ Accepted: May 9, $2014 \quad$ Online Published: June 4, 2014

doi:10.5430/sass.v1n2p73 URL: http://dx.doi.org/10.5430/sass.v1n2p73

\begin{abstract}
The implementation of University -enterprise cooperation is one of the important measures of school to train high-quality personnel and it is also a popular and accepted education in the world. It plays a very positive role to carry out this kind of education mode on the student's innovation ability and practice ability. Tourism management students are required to have better practicality and at the same time tourism industry calls for more strict requirements for school education as it is closely related to its development. Therefore, based on school-enterprise cooperation, we should carry out continuous exploration and innovation to ultimately achieve high-quality personnel to satisfy the social needs.
\end{abstract}

Keywords: Tourism Management, Three-dimensional Practical Training Mode, University-enterprise Cooperation

\section{Introduction}

Against the background of knowledge economy, University has entered the center of the development of economic society. It requires universities' continuous conduct of openness, coordination of talent cultivation, social practice, social service and mode innovation, the combination of social practice and theory to search methods in practice and improve their learning ability.

\section{The Definition and Guideline of University-enterprise Cooperation}

\subsection{The Definition of University-enterprise Cooperation}

The education of cooperation is a unique mode of education which combines learning in classed with the paid, planned and monitored work in public and private organizations. It allows the students to acquire basic practical skills in enterprise and strengthen their confidence. The full access to social environment and work could turn the knowledge at school into the practical ability which requires a long adjustment and makes full efforts for students' thought-change.

\subsection{Pursue the Guideline of the Cooperation}

National Scheme of Long-and-middle Term Educational Reform and Development Plan (2010 2020) shows the direction of the cooperation that we should set up high-quality vocational education system and we should achieve all-round consistency between education and social demands through continuously deepening educational reform and improving students' ability and teaching ability. At the same time, in the fast development of our economy, only the high-quality talents with strong practical ability could be qualified for it which calls for the change of original educational mode and active innovation to achieve dual harvests of enterprise development and school education.

\section{Exploration of Necessity of the Training Mode}

\subsection{The Cooperation is the Organic Combination between University Education and Enterprise Education}

University education focuses on knowledge which mainly refers to the acquirement, conclusion and expansion of knowledge while enterprise education focuses on the ability. But the cultivation of ability is realized by the learning 
and developing of knowledge. Pure education will not turn the learning into cultivating and will lack room for improvement because of lack of knowledge. Therefore, the two complement each other and one without the other will have a limited influence on the students.

One obvious characteristic of the major of tourism management is its practice. After graduating from college, students come into contact with society where they could not deal with interpersonal communication properly. Normalized working conditions of enterprise which exist between university and society is superior to overall social conditions. Therefore, the adoption of three-dimensional training mode aims to develop the mutual development and coordination between the two sides and satisfy the social demands for tourist talents.

\subsection{The Cooperation Could Improve the Overall Ability of Students}

The cooperation will greatly improve the practical skills of students. Through working in enterprises, students can enrich their professional knowledge, improve their practical ability, increase their high-quality professional awareness, take active study and working attitude and get close to enterprises. As students spend most of time on the practical training which is the mode of enterprise management carried out in productive labor to a large degree. The practical conditions, teaching and training method are close to enterprise which makes it easier for students to know enterprise, its working conditions and states, its employment system and its culture, thus raising the learning self-consciousness. The part-time trainers of enterprises always have great capacity of working and learning with rich teaching experience compared with practice instructors in universities. They could guarantee the practice teaching quality, strengthen their practice training and form the ability and skills step by step.

\subsection{The Cooperation Could Give Full Play to the Training Characteristics of the Major}

Education should focus on skills which mean putting students' practical skills in the first place. Only by setting up educational system with the core of vocational ability, strengthening practical skills training and cultivating skilled talents with good professional ethics could universities survive and develop. At present, teaching conditions and modes and employment are key factors that limit its development.

Despite the some advantages of universities in theories, they are limited in working practice, information exchange and working platform which are the advantages of enterprises. The cooperation should take full advantage of each other and promote the overall development of students. The enterprise staff at the production line takes part in the daily teaching in university, improve the building up of its education, and at the same time cultivating the ability of teachers to take part in enterprise development, promoting its reform and quality for further mutual development.

\section{The Problems in the Present Tourism Management Three-dimensional Practical Training Mode}

\subsection{The Low Level of University-enterprise Cooperation}

The cooperation aims to improve teaching quality and students' working ability. According to some materials, some universities are just under the cover of the cooperation. Both sides of the cooperation can't benefit from it as universities don't strive to carry out the cooperation. In the process, many problems arise such as the low level of cooperation, the disconnection of teaching and working, the lack of teaching content and corresponding practical knowledge.

\subsection{The Difficult Transform from Student to Employee}

The process of students' taking jobs is not only a transform from knowledge to practice, but also a process of becoming a qualified employee through strengthening social practice, adjusting to social development, developing team spirit and improving their working ability. Some students with poor basic knowledge and ability will confront various problems. As the majority of universities fail to monitor the students, good administrative disciplines and working qualities are not formed and many problems arise in this process

\subsection{The Small Size of Cooperating Enterprise}

Large-size enterprises will not accept the cooperation while most small-and-middle-sized enterprises prefer it that focus on the talents store. Small-size enterprises usually fail to recruit high-quality talents because of their limited ability; therefore they hope to carry out deep cooperation with universities to achieve long-term development.

\subsection{The Low Enthusiasm in Universities towards the Cooperation}

The low enthusiasm is mainly because of the unfair distribution of profits. Firstly, teachers' involvement of practice may lead to the issue of year-end performance, which is the assessment of teachers. With no objective assessment, teachers will not work actively. Underestimated, they will be unsatisfied and overestimated; they will be disliked by 
other teachers. From another point of view, the teachers involved in practice hope to create some value besides the improvement of their ability and get appropriate salary. But in the realistic process, universities are likely to reduce teachers' salary to balance it among teachers, thus reducing their enthusiasm.

Likely, students will confront many problems such as whether they should be paid, what kind of jobs they take, who should be responsible for their daily administration, what should be done if they have great performance, whether enough jobs are offered. It's just because of many problems that ill state and students' discontent appear and they drop out of the internship.

\section{The Solution to the Problems}

\subsection{Change Students' Concept.}

The majority of students think that universities as well as enterprises are profit-oriented. Just imagine what will happen if they view the cooperation with this concept. Therefore, we should make good psychological preparation through theme meetings, mobilization meetings and various lectures to let them know the aim, meaning and requirements of the internship as well as culture, vocational quality, working system, disciplines and quality standards of the enterprise. University should strengthen students' education of professional ethics, disciplines, production safety, self-protection and psychological fitness.

\subsection{Pay Attention to Methods}

The cooperation is targeted which require different educational and administrative methods according to different enterprises. Firstly, define the name of class. Name the class after the name of enterprise to give clear place and direction of students to form good team conscious. Secondly, lay out specific regulation of non-targeted program to remove the awareness that when recruited in the class, they are secured. Through the powder place elimination system, the students form good habits of actively obeying the regulations.

\subsection{Follow the Management}

In the "non-targeted program", students are specially trained, but in the early stage of the practical work, they are vulnerable to some unsettled factors. Especially the distance between work site in enterprise and the production in university will lead to a sense of loss which we call "weaning syndrome". At this time, university teachers should follow the management and require the good communication between students and staff. It is a key to the success of the cooperation.

\subsection{The Supporting System of Preferable Policies}

Due to the active role of employment, enterprises take the initiative role in the cooperation and the settled win-win system has not been set up yet. Therefore, government should issue corresponding preferable policies and encouraging measures in macroeconomic control to encourage the initiative. The right and duty of enterprise in vocational education should be defined, vocational and pre-job training should be set, guarantee system should be improved and supporting system from the aspects of policy, regulation, labor, material and resource should be enhanced. Employment system reform should be carried out deeply to make it open and recruit technicians, administrative staff and staff with special skills to teach in vocational college.

\section{The Future Trends of the Mode}

\subsection{The Application of Social Media}

The difficulty of the cooperation is just because that we consider it as "administrative affairs" instead of "common affairs" which is the product of market economy. Social media should set up platform for the enterprises and universities, thus spreading the influence of enterprise's products through universities. Media should publicize regularly and arranges specialized channel or edition to report the latest cooperation, its strengths and fruits. The enterprises realize that if they actively take part in the cooperation, they could spread the enterprise information better, demonstrate its image and shape its brand, thus improving the recognition and reputation.

\subsection{Set up Professor's Office System in Enterprise}

Setting up professor's office system in enterprise could promote the communication between teachers and enterprise through the platform. Through the system, teachers could understand the consuming organization, the development trend of enterprises, its related responsibility, employment rules and management system and the new information 
and new methods of the industry. In the office, teachers could join the discussion of products, program development, apply the new products into consumption, thus speeding up the transformation of the scientific fruits and the cooperation.

At the same time, engineers and technicians of enterprise could take part in the teaching which offers direct connection between enterprise and students and inducts students to analyze its practical situations and solve its problems. And the evaluation of lecturers and professors could encourage the enterprise staff to participate into the cooperation and enhance the cooperation.

\section{Conclusion}

This creative mode plays an important role in students' development, but it also confronts many problems at present. Therefore, it needs the joint efforts of government, society and university to cultivate high-quality talents to meet the demands of modern society.

\section{References}

Huang Yanling, Luo Shengfeng \& Wu Jin. (2010). Exploration of Teaching Practice of Tourist Undergraduates. Learning Theories, 26, 300-303.

Li Ximei, \& Sun Liuwei. (2010). The Teaching Promotion Statistics of Henan Tourism Majors. Henan Education (midmonth), 06, 21-22.

$\mathrm{Lu}$ Xiaoqin. (2011). The Research and Practice of the Cooperation Between University and Enterprise. Changjiang University (natural science edition), 02, 258-260.

Luo Dali. (2011). The Practice Exploration of Labs Set by Enterprise and University Cooperation in Higher Vocational Education-Example of Chongqing Engineering Vocational College. Tourism Survey (Industry Edition), 07, 89-90.

Peng Fenwen. (2008). Elementary Introduction to the Internship of University Tourist Students. Vocational Education Research, 05, 118-119.

Xia Xueying. (2010). The Construction of Practice Teaching System for Tourist Undergraduates. Shenyang Normal University Journal (the Edition of Education and Science), 06, 100-103.

Zhang long, \& Zheng Yaoxing. (2007).The Education Reform of University Tourism Majors. Fujian Forum (social science edition), S1, 156-158.

Zhang Shuxian, \& Liu Haiyang. (2006). The Exploration of Teaching Mode of University Tourism Majors. Changchun Normal College Journal, 06, 127-129. 